\title{
THE IMPACT OF COVID-19 PANDEMIC ON STOCK MARKET RETURN VOLATILITY: EVIDENCE FROM MALAYSIA AND SINGAPORE
}

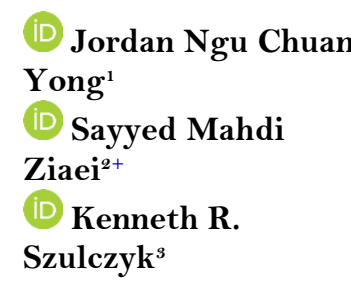

Article History

Received: 14 January 2021 Revised: 10 February 2021 Accepted: 25 February 202 Published: 8 March 2021

\section{Keywords \\ COVID19 pandemic \\ Stock returns \\ Volatility \\ GARCH family model \\ Bursa Malaysia \\ Singapore exchange.}

JEL Classification: C22; C51; C52.

\author{
${ }^{1,2, s}$ School of Economics and Management, Xiamen University Malaysia \\ Campus, Sepang, Selangor, Malaysia.

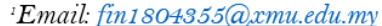 \\ EEmail:sayyed@xmu.edu.my \\ ${ }^{s}$ Email: kenneth.szulczyk@xmu.edu.my
}

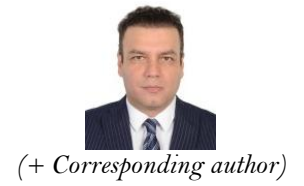

(T) Check for updates

\begin{abstract}
In this study, the volatility of two Asian stock markets, Bursa Malaysia and Singapore Exchange, is estimated. The analysis used data on daily closing prices of the indices of the respective stock markets between July 1, 2019 and August 31, 2020. The sample is split into two subsample periods: Pre-COVID-19 pandemic and during the COVID-19 pandemic. We estimated a standard GARCH, GARCH-M, TGARCH, EGARCH and PGARCH model for each subsample. We chose the best GARCH that yielded the lowest Schwarz information criterion for the normal, skewed normal, Student's tdistribution, skewed Student's t-distribution, generalized error distribution (GED) and skewed GED. The results show that both stock market returns are quite persistent, and the persistence decreases for both stock market returns during the pandemic. Furthermore, the normal distribution performed well for Malaysian and Singaporean stock markets before the pandemic and switched to a Student's t (skewed normal) during the pandemic. The standard $\operatorname{GARCH}(1,1), \operatorname{GARCH}-\mathrm{M}(1,1)$, and $\operatorname{EGARCH}(1,1)$ performed well for both stock market returns, and the EGARCH indicates the presence of the leverage effect when stock market returns are negatively correlated to its volatility.
\end{abstract}

Contribution/Originality: In this study, the volatility of the Malaysian and Singaporean stock market returns is examined and estimated with various GARCH models with different probability distributions in the loglikelihood function. The COVID-19 pandemic has altered the distributional properties of the GARCH models.

\section{INTRODUCTION}

In the financial sector, investors, financial analysts and policymakers model and forecast financial time series, such as stock returns, to ensure appropriate investment decisions are made (Abdalla \& Suliman, 2012). The volatility is one of the most important concepts involved in time series estimation and modelling as it relates to the dispersion of a financial time series and serves as a proxy for financial risk (Abdalla \& Winker, 2012). Accordingly, the volatility plays an important role in portfolio selection, derivative pricing and risk management. Although volatility plays an informative and vital role in financial markets, it is not directly observable, varies over time and is highly sensitive to financial market changes (Awalludin, Ulfah, \& Soro, 2018). Therefore, econometricians have 
developed various volatility models, since volatility estimation with the best precision is crucial in determining what is happening in the stock markets and the economy.

Engle (1982) created the first volatility model known as the autoregressive conditional heteroscedasticity (ARCH) model. Later on, Bollerslev (1986) expanded the model into the generalized autoregressive conditional heteroscedasticity $(\mathrm{GARCH})$ model. Other researchers have expanded the GARCH forms; for example, Engle, Lilien, and Robins (1987) created the GARCH-in-mean (GARCH-M) that incorporates risk. These models account for heteroscedasticity in time series because variance is treated as non-stationary. These models also capture leptokurtosis (a distribution with fat tails) and volatility clustering when time series waver between high volatility and low volatility episodes. However, they cannot model the leverage effect when a stock market's return and volatility are negatively correlated (Ugurlu, Thalassinos, \& Muratoglu, 2014). The exponential GARCH (EGARCH), threshold GARCH (TGARCH) and power GARCH (PGARCH) overcome these limitations.

A financial crisis can alter and change the nature of a stock return's volatility. For example, the World Health Organization announced on March 11, 2020 that the COVID-19 pandemic had evolved into a global crisis. This pandemic transcends the common flu that raises health complications and mortality while striking socioeconomic groups differently (United National Development Programme, 2020). Thus, the pandemic has significantly impacted the financial markets in 2020, as travel restrictions, social distancing, lockdowns and massive unemployment have struck economies.

This study aims to measure and estimate the Malaysian and Singaporean stock market volatility for the prepandemic period and during the pandemic using various GARCH models. We focused on Malaysia and Singapore because they are both growing and developing rapidly in Southeast Asia. Malaysia is the fourth largest economy of Southeast Asia and has become a leading exporter of semiconductors, electrical instruments and electronic parts, and has gained the attention of foreign investors that fuel investments into the economy. Meanwhile, Singapore is ranked among one of the world's most competitive economies. Its economy is based on international trade, its finance sector, business services, electronics and petrochemicals. Singapore is a regional commercial hub as the total volume of container transshipment traffic ranks behind Hong Kong.

Several other researchers have focused on Malaysian and Singaporean stock markets. Nor \& Shamiri (2007) discovered that the asymmetric models, such as EGARCH and GJR-GARCH, outperform the symmetric GARCH model in the Malaysian and Singaporean stock markets because asymmetric models account for leptokurtosis and the leverage effect. Shamiri \& Isa (2009) improved the conditional variance forecasting by incorporating a distribution with heavy tails and skewness in the Malaysian stock market. Furthermore, Kuen \& Hoong (1992) found the exponentially weighted moving average (EWMA) model forecast better for the Singaporean stock market than the historical sample variance and GARCH. Tan, Yahya, \& Ariffin (2012) found a positive relationship between interest rate volatility and stock market return volatility using a GARCH(1,1) model. In addition, Lim \& Sek (2013) determined that symmetric GARCH models perform better than asymmetric GARCH models during the pre- and post-crisis periods in the Malaysian stock market, while asymmetric GARCH performs better during a crisis period. Meanwhile, Angabini \& Wasiuzzaman (2011) found the Kuala Lumpur Composite Index (KLCI) returns exhibit leptokurtosis, clustering and the leverage effect, and the return volatility increased during the 2008 global financial crisis. However, no studies focused on stock market return volatility during the COVID-19 pandemic in Malaysia and Singapore.

This study aims to compare and contrast the impact of the COVID-19 pandemic on the Malaysian and Singaporean stock market returns and identify the best GARCH model and distribution that model volatility. The study examines the stock performance before and during the COVID-19 pandemic. Finally, this study determines the impact of COVID-19 on volatility clustering, leptokurtosis, and the leverage effect in the Malaysian and Singaporean stock markets. 
This study's second aim provides insight for investors in the Malaysian and Singaporean stock markets to understand and predict market volatility. Investors use volatility forecasting to render solid returns as volatility serves as a proxy for investment risk. Investors can adjust their investment strategies or hedge their investments with financial derivatives. In addition, policymakers of the Bank Negara Malaysia and the Monetary Authority of Singapore could use volatility forecasting to help maintain stock market stability during a pandemic. For example, the United States Federal Reserve considers the volatility of stocks, bonds, currencies and commodities as it drafts monetary policy (Poon \& Granger, 2003).

This study contributes to the research literature on how the COVID-19 pandemic has affected stock markets' volatility, and it shows that the pandemic has changed the characteristics of the GARCH process and its underlying distribution.

The paper has the following structure: Section 2 describes the data sources and GARCH specifications, Section 3 discusses the results, and Section 4 concludes the study.

\section{DATA AND METHODOLOGY}

Time series data from the FTSE Malaysia KLCI Index and the FTSE Straits Times Index were used to examine the stock return performance before and during the 2020 COVID-19 pandemic. Both time series are available from Yahoo Finance. The indices are daily and converted to continuous compounding by taking the log differences. The pre-pandemic sample starts on July 1, 2019 and ends on January 31, 2020, while the during pandemic period starts on February 1, 2020 and ends on August 31, 2020.

The analyses began by determining the distributional properties of the pre-, during, and full sample periods using descriptive statistics, after which stationarity and heteroscedasticity tests were performed. Estimating a GARCH requires the stock market returns to be stationary, while the heteroscedasticity test checks for the presence of the $\mathrm{ARCH}(q)$ effects in the residuals of the stock returns. Equation 1 defines the generalized autoregressive (AR) representation of the squared residuals.

$$
\widehat{u}_{t}^{2}=b_{0}+b_{1} \widehat{u}_{t-1}^{2}+b_{2} \widehat{u}_{t-2}^{2}+\cdots+b_{q} \hat{u}_{t-q}^{2}+e_{t}
$$

Parameter estimate $b$, which is statistically significant and nonzero, indicates the presence of an ARCH effect. The test statistic uses a Lagrange multiplier (LM) test in a reduced form in Equation 2. The null hypothesis is that stock returns do not exhibit an $\mathrm{ARCH}$ effect; failure to reject the null hypothesis indicates a constant variance, and hence no GARCH effects.

$$
\widehat{u}_{t}^{2}=b_{0}+b_{1} \widehat{u}_{t-1}^{2}+e_{t}
$$

Once the stock returns showed an ARCH effect, we estimated the GARCH, GARCH-M, TGARCH, EGARCH, and PGARCH. The best GARCH model was used to compare the stock market return performance between the periods before and during the COVID-19 pandemic. Last, the Malaysian and Singaporean stock returns were compared to assess the pandemic's impact on volatility.

The first GARCH that we estimated comes from Bollerslev (1986). We specified a GARCH(1,1) process because researchers found the $\mathrm{GARCH}(1,1)$ performed well during the 2008 global financial crisis in Malaysia (see, e.g., Angabini \& Wasiuzzaman, 2011; Awalludin et al., 2018; Kingsley \& Peter, 2019; Namugaya, Weke, \& Charles, 2014; Tripathy \& Rahman, 2013). Equation 3 is the mean equation with a stock market return $\left(r_{t}\right)$, intercept (c), and residual $\left(\mathrm{u}_{\mathrm{t}}\right)$, while Equation 4 represents the conditional variance equation with a variance $\left(\sigma_{t}^{2}\right)$. The conditional variance depends on the lagged squared error $u_{t-1}^{2}$ and the lagged variance term $\sigma_{t-1}^{2}$. The underlying assumption 
of the $\operatorname{GARCH}(1,1)$ is that parameters $\alpha, \theta_{1}$ and $b_{1}$ are greater than zero for a positive variance, while the stationary assumption requires that the sum $\theta_{1}+b_{1}$ is less than one (Bollerslev, 1986). The residual is related to the random noise $\left(\mathrm{z}_{\mathrm{t}}\right)$ via $\varepsilon_{t}=\sigma_{t} z_{t}$.

$$
\begin{aligned}
& r_{t}=c+u_{t} \\
& \sigma_{t}^{2}=\alpha+\theta_{1} \sigma_{t-1}^{2}+b_{1} u_{t-1}^{2}
\end{aligned}
$$

The second GARCH estimated is the GARCH-M. Engle et al. (1987) developed the symmetric mean GARCH $\left(\right.$ GARCH-M) model in Equations 5 and 6. The mean equation includes the variance $\left(\sigma_{t}^{2}\right)$ because the variance serves as a proxy for risk. Investors are risk-averse, and the parameter $\lambda$ reflects the risk premium. Consequently, investors are willing to increase their holdings in a risky asset if they earn a risk premium for doing so. The residual has the same relationship to the random noise, or $\varepsilon_{t}=\sigma_{t} z_{t}$.

$$
\begin{aligned}
& r_{t}=c+\lambda \sigma_{t}^{2}+u_{t} \\
& \sigma_{t}^{2}=\alpha+\theta_{1} \sigma_{t-1}^{2}+b_{1} u_{t-1}^{2}
\end{aligned}
$$

For the third GARCH, we estimated the TGARCH. Symmetric GARCH models do not capture the leverage effect in a financial time series and investors respond to positive information differently to negative, which induces an asymmetric impact on volatility. Zakoian (1994) came up with the threshold GARCH (TGARCH) model by adding a dummy variable in the conditional variance equation. The $\operatorname{TGARCH}(1,1)$ model is specified in Equations 7 and 8 , which show the mean and variance equations. The dummy variable, $\left(D_{t}\right)$, equals one when negative shocks occur $\left(u_{t-1}<0\right)$, and zero otherwise. Parameter $Y$ is the asymmetric or leverage effect, which implies that negative shocks have larger impacts than positive shocks.

$$
\begin{aligned}
& r_{t}=c+u_{t} \\
& \sigma_{t}^{2}=\alpha+\theta_{1} \sigma_{t-1}^{2}+b_{1} u_{t-1}^{2}+\gamma_{1} u_{t-1}^{2} D_{t-1}
\end{aligned}
$$

For the fourth GARCH, we estimated the EGARCH. Nelson (1991) introduced the exponential GARCH (EGARCH) model to capture shocks' asymmetric effects, such as new policies, news and incidents. The $\operatorname{EGARCH}(1,1)$ is shown in Equations 9 and 10. In this model, the logarithms of volatility are performed. It transforms the asymmetric effect into exponential rather than quadratic and ensures the parameter estimates are positive. Parameter $Y$ that is statistically equal to zero implies a symmetric model and a negative $Y$ indicates that negative shocks induce larger volatility than positive shocks.

$$
r_{t}=c+u_{t}
$$




$$
\log \left(\sigma_{t}^{2}\right)=\alpha+\theta_{1} \log \left(\sigma_{t-1}^{2}\right)+b_{1}\left|\frac{u_{t-1}}{\sqrt{\sigma_{t-1}^{n}}}\right|+\gamma_{1} \frac{u_{t-1}}{\sqrt{\sigma_{t-1}^{n}}}
$$

For the last GARCH, we considered the power GARCH (PGARCH) that was introduced by Taylor (2008) and Schwert (1989). This GARCH estimates the conditional standard deviation rather than the conditional variance. The PGARCH $(1,1)$ model is shown in Equations 11 and 12. The parameters $\theta_{1}, b_{1}$, and $\gamma_{1}$ represent the GARCH, $\mathrm{ARCH}$ and leverage effects, respectively. Parameter $\delta$ is the power term; when $\delta=2$, Equation 12 resembles the classic GARCH model with a leverage effect and when $\delta=1$ the model conditions volatility on the standard deviation. Ocran and Biekpe (2007) devised an algorithm to estimate $\delta$ as an endogenous parameter. A statistically significant $\gamma$ indicates that negative shocks induce greater volatility than positive shocks.

$$
\begin{aligned}
& r_{t}=c+u_{t} \\
& \sigma_{t}^{\delta}=\alpha+\theta_{1} \sigma_{t-1}^{\delta}+b_{1}\left(\left|u_{t-1}\right|-\gamma_{1} u_{t-1}\right)^{\delta}
\end{aligned}
$$

Not only can we estimate a variety of GARCH models, but we can also change the probability distribution of the log-likelihood function. Equation 13 shows the standard normal probability distributions with $\mathrm{T}$ equaling the number of observations. We also considered the skewed normal distribution with a skewness parameter.

$$
L_{\text {normal }}=-\frac{1}{2} \sum_{t=1}^{T}\left[\ln (2 \pi)+\ln \left(\sigma_{t}^{2}\right)+z_{t}\right]
$$

We also estimated the log-likelihood function using the Student's t shown in Equation 14; the degrees of freedom equal v, while $\Gamma(\cdot)$ represents the gamma function. The t-distribution has fatter tails than the normal distribution but converges to a normal distribution when the degrees of freedom become large. We also considered the skewed Student's t distribution.

$$
L_{\text {Student }} s_{t}=\ln \left[\Gamma\left(\frac{v+1}{2}\right)\right]-\ln \left[\Gamma\left(\frac{v}{2}\right)\right]-\frac{1}{2} \ln [\pi(v-2)]-\frac{1}{2} \sum_{t=1}^{T}\left[\ln \sigma_{t}^{2}+(1+v) \ln \left(1+\frac{z_{t}^{2}}{v-2}\right)\right](14)
$$

Finally, we employed the generalized error distribution (GED) that incorporates the skewness and kurtosis that financial time series often exhibit. The GED log-likelihood function is written in Equation 15 where $\lambda_{v}=\sqrt{\frac{\Gamma\left(1 / v 2^{-2 / v)}\right.}{\Gamma(3 / v)}}$, and parameter $\mathrm{v}$ represents the tail's thickness. Hamilton and Susmel (1994) provided a detailed discussion of the GED and, in this study, we also looked at the skewed GED.

$$
L_{G E D}=\sum_{t=1}^{T}\left[\ln \left(\frac{v}{\lambda_{v}}\right)-0.5\left|\frac{z_{t}}{\lambda_{v}}\right|^{v}-\left(1+v^{-1}\right) \ln (2)-\ln \Gamma\left(\frac{1}{v}\right)-0.5 \ln \left(\sigma_{t}^{2}\right)\right]
$$




\section{RESULTS AND DISCUSSION}

\subsection{Descriptive Statistics}

The analysis began with the distributional properties of the stock market returns. Figure 1 plots the Malaysian and Singaporean stock indices. Both indices plummeted in April 2020 as the COVID-19 pandemic had started. The Malaysian stock market has rebounded, while the Singaporean market remains at a lower level. Table 1 summarizes the descriptive statistics for Malaysia and Singapore. In Panel A, the mean for the Malaysian stock return is negative for all periods and is the lowest during the pre-pandemic period. Furthermore, the stock return shows the highest standard deviation during the pandemic. The kurtosis also rises greatly during the pandemic, while the negative skewness decreases. A negative skewness indicates frequent small gains and rare large losses, similar to markets experiencing a financial bubble. Finally, the Jarque-Bera statistic is statistically significant and shows the returns do not have a kurtosis and skewness that conform to a normal distribution.

In Panel B, the Singaporean stock return has the lowest mean and standard deviation during the pandemic. The kurtosis spikes during the pandemic, while the skewness becomes more negative. The null hypothesis of the JarqueBera statistic is rejected for all periods, which indicates the returns do not have a kurtosis and skewness from a normal distribution. The Singaporean stock market has a higher standard deviation than the Malaysian stock market, indicating higher risk; this could also explain why the Singaporean stock return exhibits a greater negative skewness during the pandemic.
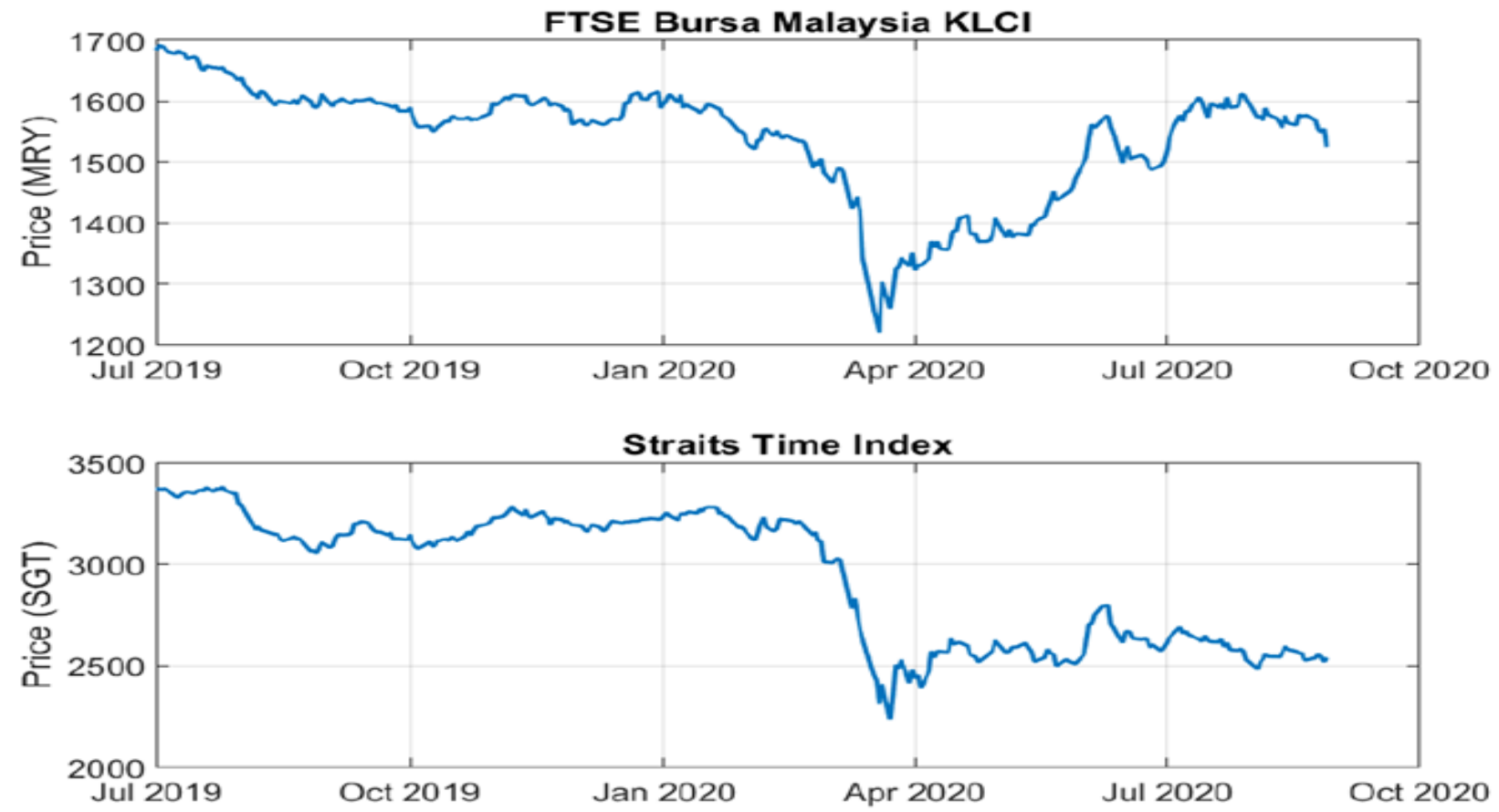

Figure 1. Malaysian and Singaporean Stock Indices.

Table 1. Descriptive statistics of the Malaysian and Singaporean stock returns.

Panel A. Malaysian Stock Returns

\begin{tabular}{l|c|c|c}
\hline Statistic & Period Before Pandemic & Period During Pandemic & Full Sample Period \\
\hline Mean & -0.0007 & -0.00003 & -0.0003 \\
\hline Median & -0.0006 & 0.0005 & -0.0001 \\
\hline Maximum & 0.0140 & 0.0663 & 0.0663 \\
\hline Minimum & -0.0168 & -0.0540 & -0.0540 \\
\hline Standard deviation & 0.0051 & 0.0141 & 0.0105 \\
\hline Skewness & -0.3745 & -0.2547 & -0.2493 \\
\hline Kurtosis & 0.9434 & 5.0965 & 9.6109 \\
\hline Jarque-Bera & $8.7662^{*} * *$ & $154.1224^{*} * *$ & $1103.6902^{*} *$ \\
\hline & $(0.0125)$ & $(0.0000)$ & $(0.0000)$ \\
\hline Number of observations & 145 & 141 & 286
\end{tabular}




\begin{tabular}{l|c|c|c}
\hline Panel B. Singaporean Stock Return \\
\hline Statistic & Period Before Pandemic & Period During Pandemic & Full Sample Period \\
\hline Mean & -0.0005 & -0.0015 & -0.0010 \\
\hline Median & -0.0001 & -0.0010 & -0.0007 \\
\hline Maximum & 0.0153 & 0.0589 & 0.0589 \\
\hline Minimum & -0.0206 & -0.0764 & -0.0764 \\
\hline Standard deviation & 0.0059 & 0.0192 & 0.0140 \\
\hline Skewness & -0.4200 & -0.7003 & -0.9778 \\
\hline Kurtosis & 0.8168 & 3.8907 & 8.7351 \\
\hline Jarque-Bera & $8.4655^{* *}$ & $100.4572^{* * *}$ & $964.8609^{* * *}$ \\
\hline \multicolumn{2}{l|}{$(0.0145)$} & $(0.0000)$ & $(0.0000)$ \\
\hline Number of observations & 148 & 141 & 289 \\
\hline
\end{tabular}

\subsection{Stationery and Heteroscedasticity Variance Tests}

In this step, we checked the stationarity of the Malaysian and Singaporean stock returns. We started by plotting the returns (see Figure 2). The stock returns vary over a narrow range before the COVID-19 pandemic for both time series and the variance widens during the pandemic. Table 2 summarizes the unit root test results for the augmented Dickey-Fuller (ADF), Phillips-Perron (PP) and Kwiatkowski-Phillips-Schmidt-Shin (KPSS) tests. All $\mathrm{ADF}$ and PP test statistics rejected the null hypothesis of unit root except the pre-pandemic Singaporean return for the ADF test. The KPSS failed to reject the null hypothesis, indicative of a stationary time series. Therefore, both the Malaysian and Singaporean stock returns are stationary, which meets the first condition to estimate the GARCH models.
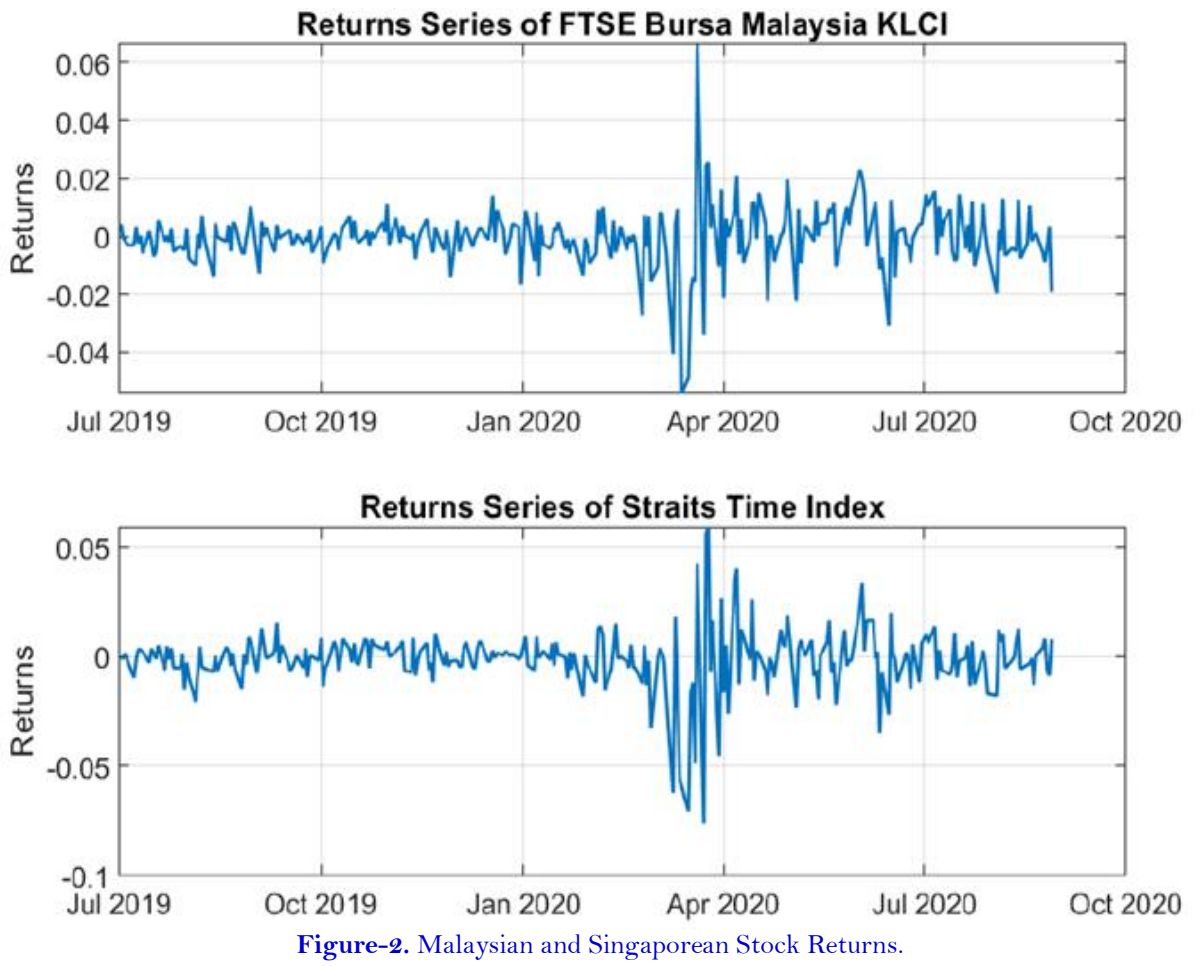

Table 2 shows the augmented Dickey-Fuller (ADF), Phillips-Perron (PP), and Kwiatkowski-Phillips-SchmidtShin (KPSS) unit root tests. The null hypothesis is the time series exhibits a unit root for the ADF and PP (fail to reject the null hypothesis), while the null hypothesis for KPSS is time series does not experience a unit root (reject the null hypothesis). 
Table 2. Unit root tests for the Malaysian and Singaporean stock returns.

\begin{tabular}{l|c|c|c}
\hline Period & ADF & PP & KPSS \\
\hline Malaysia & & & \\
\hline Before Pandemic & $-3.2660(5)^{*}$ & $-185.7000(4)^{* * *}$ & $0.1369(4)$ \\
\hline During Pandemic & $-4.3707(5)^{* * *}$ & $-154.3000(4)^{* * *}$ & $0.16536(4)$ \\
\hline Full Sample & $-6.0314(6)^{* * *}$ & $-328.4500(5)^{* * *}$ & $0.12073(5)$ \\
\hline Singapore & & & \\
\hline Before Pandemic & $-2.9029(5)$ & $-160.1200(4)^{* * *}$ & $0.18173(4)$ \\
\hline During Pandemic & $-4.1403(5)^{* * *}$ & $-174.0600(4)^{*} * *$ & $0.14782(4)$ \\
\hline Full Sample & $-6.9496(6)^{* * *}$ & $-365.8000(5)^{* * *}$ & $0.0563(5)$ \\
\hline
\end{tabular}

$1 \%$ significance levels are denoted by $* * *$ and $* * *$, respectively.

The next test determines whether the residuals exhibit a heterogeneous variance. Table 3 shows the LM test for $\mathrm{ARCH}(1)$. Both statistics reject the null hypothesis of a homogeneous variance, thus both stock returns exhibit heteroscedasticity, which meets the second condition to estimate GARCH models.

Table 3. Testing for ARCH effects.

\begin{tabular}{l|c|c}
\hline \multirow{2}{*}{} & \multicolumn{2}{|c}{ Stock Market Returns } \\
\cline { 2 - 3 } & $31.6763^{* * *} *$ & Singapore \\
\hline ARCH-LM Test Statistic & $(0.0000)$ & $37.7578^{* * *}$ \\
\hline \multicolumn{2}{|c}{ Note: The $10 \%, 5 \%$ and $1 \%$ significance levels are denoted by *,** and ${ }^{* * *}$, respectively. The null hypothesis: The error variance is homoscedastic. }
\end{tabular}

\subsection{GARCH Results and Discussion}

In this section, the parameter estimates for the standard GARCH, GARCH-M, TGARCH, EGARCH and PGARCH models are estimated for the Malaysian and Singaporean stock returns. Table 4 shows the parameter estimates of the Malaysian stock returns, while Table 5 shows the parameter estimates for the Singaporean stock returns.

According to Table 4, we can see that the Student's t distribution provides the lowest SIC for each GARCH for both the full sample and during the pandemic for the Malaysian stock market. However, the normal and GED are the distributions of choice for the pre-pandemic period. The Student's t provides a better fit because it has fatter tails than the Gaussian normal distribution. The fatter tails suggest leptokurtosis, and the shape parameter estimates are approximately four for each GARCH.

Table 4. GARCH estimation for the Malaysian stock returns.

\begin{tabular}{|c|c|c|c|c|c|}
\hline \multicolumn{6}{|c|}{ Panel A. Malaysian Returns (full sample) } \\
\hline \multirow{2}{*}{ Coefficient } & \multicolumn{5}{|l|}{ Models } \\
\hline & $\operatorname{GARCH}(1,1)$ & GARCH-M(1,1) & TGARCH(1,1) & $\operatorname{EGARCH}(1,1)$ & PGARCH $(1,1)$ \\
\hline Prob. Dist. & Student's t & Student's t & Student's t & Student's t & Student's t \\
\hline \multicolumn{6}{|c|}{ Mean Equation } \\
\hline$c$ & -0.0003 & $-0.0010^{*} *$ & -0.0003 & -0.0003 & $-0.0003^{*} * *$ \\
\hline$\lambda$ & - & 8.6261 & - & - & - \\
\hline \multicolumn{6}{|c|}{ Conditional Variance Equation } \\
\hline$\alpha$ & 0.0000 & $1.62 \mathrm{e}-6^{*}$ & 0.0002 & $-0.2794^{*}$ & 0.0010 \\
\hline$\theta_{1}$ & $0.8525^{* * * *}$ & $0.8868^{* * * *}$ & $0.8759^{* * * *}$ & $0.9700^{* * * * *}$ & $0.8768^{* * * *}$ \\
\hline$b_{1}$ & 0.1465 & $0.1046^{* * *}$ & $0.1462^{*}$ & 0.0052 & $0.1368^{*}$ \\
\hline$\gamma_{1}$ & - & - & 0.0487 & $0.3245^{* * * *}$ & 0.0470 \\
\hline
\end{tabular}


Asian Economic and Financial Review, 2021, 11(3): 191-204

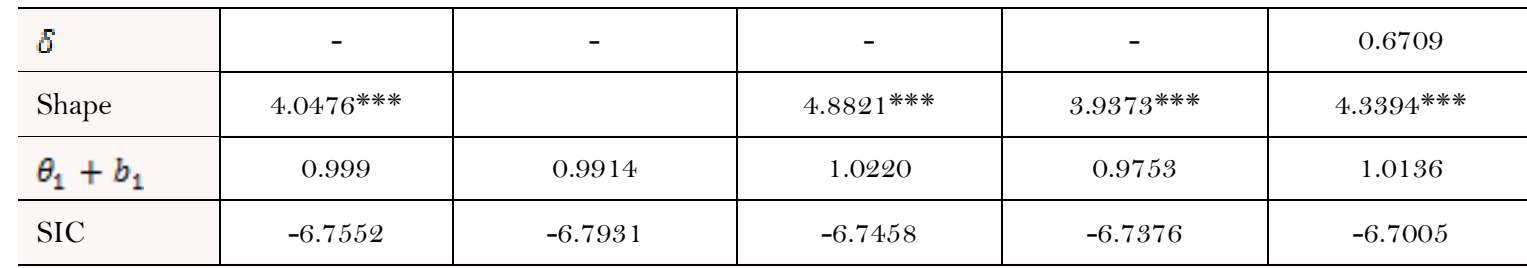

Panel B. Malaysian Returns (pre-pandemic)

\begin{tabular}{|c|c|c|c|c|c|}
\hline \multirow{2}{*}{ Coefficient } & \multicolumn{5}{|l|}{ Model } \\
\hline & $\operatorname{GARCH}(1,1)$ & GARCH-M(1, 1) & TGARCH( 1,1$)$ & $\operatorname{EGARCH}(1,1)$ & $\operatorname{PGARCH}(1,1)$ \\
\hline Prob. Dist. & Normal & Normal & GED & Normal & GED \\
\hline \multicolumn{6}{|c|}{ Mean Equation } \\
\hline c & -0.0007 & $-0.0020^{*}$ & $-0.0006^{*}$ & -0.0005 & -0.0005 \\
\hline$\lambda$ & - & 37.3310 & - & - & - \\
\hline \multicolumn{6}{|c|}{ Conditional Variance Equation } \\
\hline$\alpha$ & 0.0000 & $1.09 \mathrm{e}-6^{* * * *}$ & 0.0000 & $-5.5630^{*}$ & 0.0000 \\
\hline$\theta_{1}$ & $0.9990^{* * * *}$ & $0.9984^{* * * *}$ & 0.9990* $* * *$ & $0.4736^{* *}$ & $0.9044^{* * * * *}$ \\
\hline$b_{1}$ & 0.0000 & $-0.0369^{* *}$ & 0.0000 & $0.2206^{*}$ & 0.0414 \\
\hline$\gamma_{1}$ & - & - & -0.7173 & 0.2940 & -0.2405 \\
\hline$\delta$ & - & - & - & - & $2.7829^{* * * *}$ \\
\hline Shape & - & - & $1.4509^{* * * *}$ & - & $1.3044^{*} * * *$ \\
\hline$\theta_{1}+b_{1}$ & 0.9990 & 0.9616 & 0.9990 & 0.6941 & 0.9459 \\
\hline SIC & -7.5852 & -7.6962 & -7.5657 & -7.5841 & -7.5107 \\
\hline
\end{tabular}

Panel C. Malaysian Returns (during pandemic)

\begin{tabular}{l|c|c|c|c|c}
\hline \multirow{2}{*}{ Coefficient } & \multicolumn{1}{|l}{ Model } \\
\cline { 2 - 6 } & GARCH(1,1) & GARCH-M(1,1) & TGARCH(1,1) & EGARCH(1,1) & PGARCH(1,1) \\
\hline Prob. Dist. & Student's t & Normal & Student's t & Student's t & Student's t \\
\hline
\end{tabular}

Mean Equation

\begin{tabular}{l|c|c|c|c|c}
\hline$c$ & 0.0007 & -0.0006 & 0.0006 & $0.0006^{*}$ & 0.0007 \\
\hline$\lambda$ & - & 8.29026 & - & - & - \\
\hline
\end{tabular}

\begin{tabular}{|c|c|c|c|c|c|}
\hline \multicolumn{6}{|c|}{ Conditional Variance Equation } \\
\hline$\alpha$ & 0.0000 & $1.87 \mathrm{e}-5$ & 0.0015 & -1.0141 & 0.0000 \\
\hline$\theta_{1}$ & $0.7019^{* * *}$ & $0.7438^{* * * *}$ & $0.7640^{*} * *$ & $0.8827^{* * * * *}$ & $0.694 \mathrm{O}^{* * * *}$ \\
\hline$b_{1}$ & $0.1747^{*}$ & $0.1463^{*} *$ & 0.1625 & 0.0022 & 0.1726 \\
\hline$\gamma_{1}$ & - & - & 0.1331 & $0.3614^{*}$ & -0.0028 \\
\hline$\delta$ & - & - & - & - & $2.1124^{\text {***** }}$ \\
\hline Skewness & - & - & - & - & - \\
\hline Shape & $4.3303^{* * * *}$ & & $4.5647^{* * * *}$ & $4.0618^{* * * * *}$ & $4.3124^{* * *}$ \\
\hline$\theta_{1}+b_{1}$ & 0.8766 & 0.8901 & 0.9265 & 0.8849 & 0.8666 \\
\hline $\mathrm{SIC}$ & -5.8500 & -5.8638 & -5.8102 & -5.8031 & -5.7799 \\
\hline
\end{tabular}

Note: Table 4 shows the parameter estimates of the Malaysian stock returns for the standard GARCH(1,1), GARCH-M(1,1), TGARCH(1,1), EGARCH(1,1) and PGARCH(1,1). Each GARCH was estimated with the Gaussian normal, skewed normal, Student's t, skewed Student's t, generalized error distribution (GED) and skewed generalized error distribution. An algorithm chose the best fitting distribution for each GARCH that yielded the lowest SIC. The 10\%, $5 \%$ and $1 \%$ significance levels are denoted by * ** and ****, respectively. 
The first discernable pattern shows that the $\lambda$ parameter estimate is positive for the full, pre- and during pandemic sample periods for the Malaysian stock returns. However, the parameter estimate is not statistically significant, and thus the null hypothesis of the parameter equaling zero is not rejected. Second, the parameter estimate $\theta_{1}$ is positive and statistically significant in all GARCH models for all sample periods. The $\theta_{1}$ parameter reflects persistence in volatility and indicates a long memory process. Third, the parameter estimate $b_{1}$ is statistically significant in the GARCH-M and EGARCH models for the pre-pandemic period and standard GARCH and GARCH-M during the pandemic. The $\mathrm{b}_{1}$ parameter reflects shocks to the stock market return and, ironically, the magnitudes are greater during the pre-pandemic period than during the pandemic. Finally, the sum $\theta_{1}+b_{1}$ must be lower than one to satisfy the stationary condition (Chan, 2011). Both the TGARCH and PGARCH violate this assumption in the full sample period. For the other GARCH models the sum is close to one and indicates a long memory process in volatility. One noticeable effect is the $\theta_{1}+b_{1}$ becomes smaller during the pandemic. This unusual result could occur from the rebounding stock market during the pandemic.

The results show the TGARCH and PGARCH are not possible candidates because the sum, $\theta_{1}+b_{1}$, violates the stationary condition. The standard GARCH, GARCH-M and EGARCH are possible candidates. For the EGARCH, the parameter estimate $\gamma_{1}$ is positive and statistically significant in the full and during pandemic samples, and therefore indicates the presence of the leverage effect.

Table 5 shows the parameter estimates for the standard GARCH, GARCH-M, TGARCH, EGRACH and PGARCH models for the Singaporean stock returns. For the full sample, the Student's $\mathrm{t}$ distribution yielded the smallest SIC. However, the normal distribution is the best distribution for the pre-pandemic sample, while the skewed normal distribution yielded the lowest SIC during the pandemic. This unusual result could originate from the Singaporean stock market plummeting in value during the pandemic, and it did not recover during the sample period.

The GARCH results of the Singaporean stock returns show several prominent features. First, the risk premium $\lambda$ is not statistically significant, even though the parameter estimate has the correct signs in the periods before and during the pandemic. Consequently, the null hypothesis of the parameter equaling zero is not rejected. Second, the parameter estimate $\theta_{1}$ is positive and statistically significant in all models. The results indicate that the persistence increased during the pandemic. Third, the parameter estimate $b_{1}$ is positive and statistically significant in most models for the full and during pandemic sample periods. The magnitude of the shock parameter becomes statistically significant and large during the pandemic, which is the result we would expect. Last, the sum $\theta_{1}+b_{1}$ became smaller during the pandemic and reflects a decrease in the long memory process, which is similar to the Malaysian results.

We eliminated the TGARCH because the sum $\theta_{1}+b_{1}$ exceeds one, leaving the standard GARCH, GARCH-M, EGARCH and PGARCH. Many of the parameter estimates are statistically significant in the remaining models, including the $\gamma_{1}$ and $\delta$ parameters. That means both the Malaysian and Singaporean stock market returns exhibit a leverage effect.

This paper's results support other researchers, such as the study by Lim and Sek (2013) on the Malaysian stock market. Symmetric GARCH models performed better than asymmetric GARCH models during the pre- and postcrisis periods, but the asymmetric models performed better during a crisis. The work of Tan et al. (2012) used the standard $\operatorname{GARCH}(1,1)$ and found a positive relationship between interest rate volatility and stock market return volatility for both Malaysia and Singapore. In addition, Liu, Lee, \& Lee (2009) estimated the standard GARCH in China with a skewed GED distribution. Last, Angabini \& Wasiuzzaman (2011) showed the GARCH(1,1), EGARCH(1,1) and GJR-GARCH(1,1) provide a good fit for the Malaysian stock market returns with volatility rising during the 2008 global financial crisis. 
Table 5. GARCH estimation for the Singaporean stock returns.

\begin{tabular}{|c|c|c|c|c|c|}
\hline \multicolumn{6}{|c|}{ Panel A. Singaporean Returns (full sample) } \\
\hline \multirow{2}{*}{ Coefficient } & \multicolumn{5}{|l|}{ Models } \\
\hline & $\operatorname{GARCH}(1,1)$ & GARCH-M(1,1) & TGARCH(1,1) & $\operatorname{EGARCH}(1,1)$ & $\operatorname{PGARCH}(1,1)$ \\
\hline Prob. Dist. & Student's t & Student's t & Student's t & Student's t & Student's t \\
\hline \multicolumn{6}{|c|}{ Mean Equation } \\
\hline$c$ & -0.0001 & -0.0002 & -0.0004 & -0.0004 & -0.0003 \\
\hline$\lambda$ & - & -0.1433 & - & - & - \\
\hline \multicolumn{6}{|c|}{ Conditional Variance Equation } \\
\hline$\alpha$ & 0.0000 & $3.38 \mathrm{e}-6^{*}$ & $0.0004^{*}$ & $-0.3703^{*}$ & 0.0001 \\
\hline$\theta_{1}$ & $0.7544^{* * * *}$ & $0.7877^{*} * *$ & $0.8315^{* * *}$ & $0.9601 * * *$ & $0.8156^{* * *}$ \\
\hline$b_{1}$ & $0.2354^{* * * *}$ & $0.1993^{* * * *}$ & $0.1729 * * *$ & -0.0900 & $0.1815^{* * *}$ \\
\hline$\gamma_{1}$ & - & - & $0.3655^{*}$ & $0.3633^{* * *}$ & 0.2841 \\
\hline$\delta$ & - & - & - & - & $1.3854^{* * * *}$ \\
\hline Shape & $6.2819^{* * * *}$ & & $5.7568^{* * * *}$ & $5.9706^{* * *}$ & $6.2201 * * *$ \\
\hline$\theta_{1}+b_{1}$ & 0.9898 & 0.9870 & 1.0044 & 0.8701 & 0.9971 \\
\hline SIC & -6.4030 & -6.3928 & -6.3925 & -6.3822 & -6.3757 \\
\hline
\end{tabular}

Singaporean (before pandemic)

\begin{tabular}{|c|c|c|c|c|c|}
\hline \multirow{2}{*}{ Coefficient } & \multicolumn{5}{|l|}{ Models } \\
\hline & $\operatorname{GARCH}(1,1)$ & GARCH-M(1,1) & TGARCH( $(1,1)$ & $\operatorname{EGARCH}(\mathbf{1 , 1})$ & $\operatorname{PGARCH}(1,1)$ \\
\hline Prob. Dist. & Normal & GED & Normal & Skewed Normal & Normal \\
\hline \multicolumn{6}{|c|}{ Mean Equation } \\
\hline$c$ & -0.0004 & -0.0067 & -0.0004 & 0.0000 & -0.0002 \\
\hline$\lambda$ & - & 1.0766 & - & - & - \\
\hline \multicolumn{6}{|c|}{ Conditional Variance Equation } \\
\hline$\alpha$ & 0.0000 & $5.27 \mathrm{e}-6$ & 0.0009 & $-0.2587 * * *$ & 0.0000 \\
\hline$\theta_{1}$ & $0.9799^{* * * *}$ & $0.8827 * * *$ & $0.8217 * * *$ & $0.9795 * * *$ & $0.9086 * * *$ \\
\hline$b_{1}$ & 0.0000 & -0.0344 & 0.0338 & 0.0029 & 0.0308 \\
\hline$\gamma_{1}$ & - & - & 1.0000 & $-0.1533 * * *$ & 0.1673 \\
\hline$\delta$ & - & - & - & - & $2.8238 * * *$ \\
\hline Skewness & - & - & - & $0.9244 * * *$ & - \\
\hline$\theta_{1}+b_{1}$ & 0.9799 & 0.8483 & 0.8555 & 0.9785 & 0.9394 \\
\hline $\mathrm{SIC}$ & -7.3060 & -7.2354 & -7.2941 & -7.3048 & -7.2185 \\
\hline
\end{tabular}

Singaporean Returns (during pandemic)

\begin{tabular}{l|l|l|l|l|l}
\hline \multirow{2}{*}{ Coefficient } & \multicolumn{4}{|l}{ Models } \\
\cline { 2 - 6 } & GARCH(1,1) & GARCH-M(1,1) & TGARCH(1,1) & EGARCH(1,1) & PGARCH(1,1) \\
\hline Prob. Dist. & Skewed Normal & GED & Skewed Normal & Skewed Normal & Skewed Normal \\
\hline Mean Equation
\end{tabular}




\begin{tabular}{|c|c|c|c|c|c|}
\hline$c$ & $-0.0020^{*}$ & -0.0018 & $-0.0031 * * *$ & $-0.0027 * * *$ & $-0.0019^{*}$ \\
\hline$\lambda$ & - & 3.2061 & - & - & - \\
\hline \multicolumn{6}{|c|}{ Conditional Variance Equation } \\
\hline$\alpha$ & 0.0000 & $2.11 \mathrm{e}-5$ & $0.0021 * *$ & -0.8775 & 0.0000 \\
\hline$\theta_{1}$ & $0.5940 * * *$ & $0.6696^{* * *}$ & $0.6493 * * * 2$ & $0.8919 * * *$ & $0.4782^{* * *}$ \\
\hline$b_{1}$ & $0.3229^{* *}$ & $0.2628^{*}$ & $0.3003^{* * *}$ & -0.0707 & $0.3018^{* *}$ \\
\hline$\gamma_{1}$ & - & - & 0.1710 & $0.5672^{* * *}$ & 0.0213 \\
\hline$\delta$ & - & - & - & - & $3.0726^{* * *}$ \\
\hline Skewness & $0.6811^{* * *}$ & - & $0.7007^{* * * *}$ & $0.7000^{* * *}$ & $0.7192^{* * *}$ \\
\hline$\theta_{1}+b_{1}$ & 0.9269 & 0.9324 & 0.9496 & 0.8212 & 0.7800 \\
\hline SIC & -5.4778 & -5.4136 & -5.4165 & -5.4211 & -5.4090 \\
\hline
\end{tabular}

Note: Table 5 shows the parameter estimates of the Singaporean stock returns for the standard GARCH(1,1), GARCH-M(1,1), TGARCH(1,1), EGARCH(1,1) and PGARCH(1,1). Each GARCH is estimated with the Gaussian normal, skewed normal, Student's t, skewed Student's t, generalized error distribution (GED) and skewed generalized error distribution. An algorithm chose the best fitting distribution that yielded the lowest SIC. The $10 \%, 5 \%$ and $1 \%$ significance levels are denoted by $*$, **, and ***, respectively.

This paper's results corroborate the heavy tails in the log-likelihood function. The study by Shamiri and Isa (2009) on Malaysia suggested using a heavy-tailed distribution rather than the Gaussian normal distribution. Other researchers found stock market returns are highly persistent; Abdalla \& Winker (2012) discovered the Cairo and Alexandria Stock Exchange (CASE) is quite persistent. Ugurlu et al. (2014) found persistence in the Czech Republic (PX), Poland (WIG), Hungary (BUX) and Turkey (XU100) stock markets, while Maqsood, Safdar, Shafi, \& Lelit (2017) discovered persistence in the Nairobi Securities Exchange (NSE). We should note that Abdalla \& Winker (2012) have observed that the Khartoum Stock Exchange (KSE) shows an explosive process, which the TGARCH exhibits in this study.

This study's results also support the literature of the leverage effect. For example, Nor \& Shamiri (2007) determined that the EGARCH and GJR-GARCH outperformed the standard GARCH in volatility estimation in both the Malaysian and Singaporean stock markets. Alberg, Shalit, \& Yosef (2008); Ogum, Beer, \& Nouyrigat (2005); Abdalla \& Suliman (2012) and Lupu \& Tudor (2008) found the leverage effect in the Tel Aviv Stock Exchange Index, Kenyan Stock Exchange, Saudi Tadawul All Share Index and Bucharest Exchange Trading Index.

\section{CONCLUSION}

Over the last few decades, the estimation and forecasting volatility of the financial data is a hot topic in the finance field and has attracted considerable attention from financial analysts and econometricians. This is due to the importance of volatility in asset pricing, risk management and portfolio selection and allocation. This study proves that it is better to incorporate the GARCH effect in the volatility estimation since volatility clustering is found in both markets regardless of a change in economic situation, such as that brought about by the COVID-19 pandemic. Therefore, risk management is crucial, especially for those individuals and organizations exposed to market risk since market volatility tends to rise during a pandemic.

The results showed that the Malaysian and Singaporean stock returns do not have a kurtosis and skewness from a normal distribution. Both returns exhibited heteroscedasticity and stationarity, and, consequently, the distributions showed leptokurtosis. Furthermore, the results indicated that the distribution yielding the lowest SIC in the log-likelihood function switched during the pandemic. The GARCH models were best represented by the normal and GED distributions for the pre-pandemic period in the Malaysian stock market but switched to the Student's t during the pandemic. On the other hand, the Singaporean stock market performed better with the prepandemic's normal distribution and changed to a skewed normal during the pandemic. 
This study concludes that the standard GARCH, GARCH-M and EGARCH performed well in the periods before and during the pandemic. Furthermore, the GARCH models for both the Malaysian and Singaporean stock returns indicated persistence and volatility with a long memory process. Both stock markets exhibited a lower persistence during the COVID-19 pandemic than during the pre-pandemic period. This result holds even though the Malaysian stock market has recovered from the pandemic, while the Singaporean market did not recover. Consequently, Malaysian investors could earn capital gains by going long in the Malaysian stock market.

The results showed that the GARCH-M(1,1) model estimated positive risk premiums for both the Malaysian and Singaporean stock returns, but the parameter estimates are not statistically significant. In summary, the symmetric GARCH and GARCH-M and the asymmetric EGARCH performed well, while the EGARCH indicated the presence of the leverage effect in both the Malaysian and Singaporean stock markets.

Funding: This work was supported by Xiamen University Malaysia Research Fund (XMUMRF/2018-C2/ISEM/0003).

Competing Interests: The authors declare that they have no competing interests.

Acknowledgement: All authors contributed equally to the conception and design of the study.

\section{REFERENCES}

Abdalla, S. Z. S., \& Suliman, Z. (2012). Modelling stock returns volatility: Empirical evidence from Saudi stock exchange. International Research Journal of Finance and Economics, 85(2012), 166-179.

Abdalla, S. Z. S., \& Winker, P. (2012). Modelling stock market volatility using univariate GARCH models: Evidence from Sudan and Egypt. International Journal of Economics and Finance, 4(8), 161-176.Available at: https://doi.org/10.5539/ijef.v4n8p161.

Alberg, D., Shalit, H., \& Yosef, R. (2008). Estimating stock market volatility using asymmetric GARCH models. Applied Financial Economics, $18(15), 1201-1208$.

Angabini, A., \& Wasiuzzaman, S. (2011). GARCH models and the financial crisis-a study of the Malaysian. The International Journal of Applied Economics and Finance, 5(3), 226-236.

Awalludin, S., Ulfah, S., \& Soro, S. (2018). Modeling the stock price returns volatility using GARCH $(1,1)$ in Some Indonesia Stock Prices. Paper presented at the Journal of Physics: Conference Series.

Bollerslev, T. (1986). Generalized autoregressive conditional heteroskedasticity. Journal of Econometrics, 31(3), 307-327.

Chan, N. H. (2011). Time series: Applications to finance with R and S-Plus (3rd ed. Vol. 837). New York: John Wiley \& Sons.

Dickey, D. A., \& Fuller, W. A. (1981). Likelihood ratio statistics for autoregressive time series with a unit root. Econometrica, 49(4), 1057-1072.

Engle, R. F. (1982). Autoregressive conditional heteroscedasticity with estimates of the variance of United Kingdom Inflation. Econometrica: Journal of the Econometric Society, 5O(4), 987-1007.Available at: https://doi.org/10.2307/1912773.

Engle, R. F., Lilien, D. M., \& Robins, R. P. (1987). Estimating time varying risk premia in the term structure: The A RCH-M Model. Econometrica: Journal of the Econometric Society, 55(2), 391-407.Available at: https://doi.org/10.2307/1913242.

Hamilton, J. D., \& Susmel, R. (1994). Autoregressive conditional heteroskedasticity and changes in regime. Journal of Econometrics, 64(1-2), 307-333.

Kingsley, A., \& Peter, U. (2019). Volatility modelling using ARCH and GARCH Models: A case study of the nigerian stock exchange. International Journal of Mathematics, Trends, and Technology, 65(4), 58-63.

Kuen, T. Y., \& Hoong, T. S. (1992). Forecasting volatility in the singapore stock market. Asia Pacific Journal of Management, 9(1), $1-13$.

Kwiatkowski, D., Phillips, P. C., Schmidt, P., \& Shin, Y. (1992). Testing the null hypothesis of stationarity against the alternative of a unit root: How sure are we that economic time series have a unit root? Journal of Econometrics, 54(1-3), 159-178.

Lim, C. M., \& Sek, S. K. (2013). Comparing the performances of GARCH-type models in capturing the stock market volatility in Malaysia. Procedia Economics and Finance, 5(2013), 478-487. 
Liu, H.-C., Lee, Y.-H., \& Lee, M.-C. (2009). Forecasting China stock markets volatility via GARCH models under skewed-GED Distribution. Journal of Money, Investment and Banking, 7(1), 542-547.

Lupu, R., \& Tudor, C. (2008). Direction of change at the bucharest stock exchange. Romanian Economic Journal, 1 (27), 165-185.

Maqsood, A., Safdar, S., Shafi, R., \& Lelit, N. J. (2017). Modeling stock market volatility using GARCH Models: A case study of nairobi securities exchange (NSE). Open Journal of Statistics, 7(2), 369-381.

Namugaya, J., Weke, P. G., \& Charles, W. (2014). Modelling volatility of stock returns: Is GARCH $(1,1)$ enough? International Journal of Sciences: Basic and Applied Research, 16(2), 216-223.

Nelson, D. B. (1991). Conditional heteroskedasticity in asset returns: A new approach. Econometrica, 59(2), 347-370.Available at: https://doi.org/10.2307/2938260.

Nor, A. H. S. M., \& Shamiri, A. (2007). Modeling and forecasting volatility of the Malaysian and the Singaporean stock indices using asymmetric GARCH models and non-normal densities. Malaysian Journal of Mathematical Sciences, 1(1), 83-102.

Ocran, M. K., \& Biekpe, N. (2007). Forecasting volatility in Sub-Saharan Africa's commodity markets. Investment Management and Financial Innovations, 4(2), 91-102.

Ogum, G., Beer, F., \& Nouyrigat, G. (2005). Emerging equity market volatility: An empirical investigation of markets in Kenya and Nigeria. Journal of African Business, 6(1-2), 139-154.Available at: https://doi.org/10.1300/j156v06n01_08.

Phillips, P. C., \& Perron, P. (1988). Testing for a unit root in time series regression. Biometrika, 75(2), 335-346.

Poon, S.-H., \& Granger, C. W. (2003). Forecasting volatility in financial markets: A review. Journal of Economic Literature, 41(2), 478-539.

Schwert, G. W. (1989). Why does stock market volatility change over time? The Journal of Finance, 44(5), 1115-1153.Available at: https://doi.org/10.1111/j.1540-6261.1989.tbo2647.x.

Shamiri, A., \& Isa, Z. (2009). Modeling and forecasting volatility of the Malaysian stock markets. Journal of Mathematics and Statistics, 5(3), 234-240.Available at: https://doi.org/10.3844/jmssp.2009.234.240.

Tan, K., Yahya, M. H., \& Ariffin, A. N. B. (2012). The effects of interest rates volatility on stock market returns in Malaysia and Singapore. International Journal of Management Studies, 19(1), 37-51.

Taylor, S. J. (2008). Modelling financial time series. New York: Wiley.

Tripathy, S., \& Rahman, A. (2013). Forecasting daily stock volatility using GARCH model: A comparison between BSE and SSE. IUP Journal of Applied Finance, 19(4), 71-83.

Ugurlu, E., Thalassinos, E., \& Muratoglu, Y. (2014). Modeling volatility in the stock markets using GARCH models: European emerging economies and Turkey. International Journal of Economics \& Business Administration (IJEBA), 2(3), 7287.Available at: https://doi.org/10.35808/ijeba/49.

United National Development Programme. (2020). COVID-19 pandemic: Humanity needs leadership and solidarity to defeat the coronavirus. Retrieved from https://www.undp.org/content/undp/en/home/coronavirus.html.

Zakoian, J.-M. (1994). Threshold heteroskedastic models. Journal of Economic Dynamics and control, 18(5), 931-955.Available at: https://doi.org/10.1016/0165-1889(94)90039-6.

Views and opinions expressed in this article are the views and opinions of the author(s), Asian Economic and Financial Review shall not be responsible or answerable for any loss, damage or liability etc. caused in relation to/arising out of the use of the content. 